\title{
Iranian Journal of
}

Educational

Sociology

\section{Iranian journal of educational Sociology}

(Interdisciplinary Journal of Education)

Available online at: http://www.iase-idje.ir/

Volume 2, Number 3, September 2019

\section{Identifying Dimensions and Components of Human Resource Efficiency in Medical Universities of Iran: To Present a Conceptual Model}

\author{
Ali Javadian ${ }^{1}$, Asadollah Mehrara ${ }^{2 *}$, Seyed Alireza Ebrahimi ${ }^{2}$, Mohammad Reza Bagherzadeh $^{2}$ \\ 1. PhD Student in Public Administration, Islamic Azad University, Ghaemshahr Branch, Ghaemshahr, Iran. \\ 2. Department of Management, Assistant Professor, Qaemshahr Branch, Islamic Azad University, Qaemshahr, Iran
}

\section{Article history:}

Received date: 18 March 2019

Review date: 23 June 2019

Accepted date: 23 Aguste 2019

\begin{abstract}
Purpose: The purpose of this research is identifying Dimensions and Components of Human Resource Efficiency in Medical Universities of Iran: To Present a Conceptual Model.

Methodology: The purpose of this study was applied and mixed quantitative and qualitative research and correlation and fuzzy Delphi method. The statistical population of the study consisted of 27 experts who were involved in decision making in identifying indices and dimensions of variables. Census method was used to determine sample size and snowball and census sampling method was used.
\end{abstract}

Findings: Research findings showed that HRM indices consist of seven main categories (structural-managerial, socio-psychological, cultural, individual, economic, environmental, intimate and cooperative) and 56 sub-subgroups. These findings were obtained through three stages of sweep of expert questionnaires, fuzzy and fuzzy response questionnaires.

Conclusion: The results of the research indicate that it is possible to improve the skills of the staff and increase the productivity of human resources by their appropriate training, guidance and participation.

\footnotetext{
Please cite this article: Javadian A, Mehrara A, Ebrahimi S A, Bagherzadeh M R. (2019). Identifying Dimensions and Components of Human Resource Efficiency in Medical Universities of Iran: To Present a Conceptual Model, Iranian journal of educational Sociology. 2(3):1- 11.
}

\footnotetext{
* Corresponding Author Email: mehrara_a@yahoo.com
} 


\section{Introduction}

Productivity is one of the concepts that has been going on for more than 5 years from the first scientific endeavor around it (Taheri, 2017) and has always been of interest to various scientific societies and nations. Productivity is expressed by the ratio of the desired outputs (outputs) to the resources and what is spent on the output (data). This ratio is one of the most important indicators that show the productivity of activities. In today's highly competitive world, productivity as a philosophy and vision based on improvement strategy is the most important goal in any organization and can be a chain of activities of all sectors of society (Taheri, 2017; Bahmani and Fojali, 2017). So that the management mission and the main goal of the managers of every organization is to make efficient and efficient use of various resources and facilities such as labor, capital, materials, energy and information (Alnadi, 2019).

This has made productivity and proper use in all countries a national priority, and better and more appropriate than the sum of the factors of production (both goods and services), and all societies believe that the viability of any society regardless of The issue of productivity is not possible (Terzieo, Banabakoa, Gorgieo, 2018). The most important factor in improving productivity in any organization and in any country is manpower. This factor has become an essential element in explaining the differences in productivity and growth in different countries. Organizations that have had significant successes and those that are among the developed countries have put this issue at the forefront of their work (Mash \& Adler, 2018).

Universities are the major centers of knowledge production and dissemination. Creating innovations and creating new knowledge is one of the most important functions and goals of higher education institutions and has the utmost importance for the academic community to enhance knowledge and enhance intellectual capital through the use of information resources and intellectual and human resources. This can be achieved by applying the correct knowledge practices to the goals of the organization (Ahmadi, 2016). A healthy and desirable organizational climate, with genuine and genuine interpersonal relationships, creates a situation in which professional leadership and management can be successful. In dynamic and organic organizations such as educational organizations and universities, a coherent and supportive culture of innovation culture must emerge, given the rapid changes and new technologies required to keep pace with educational changes and innovations, Creating a favorable environment for creativity and innovation in organizations. Organizations can manage knowledge in order to develop and share information. Unfortunately, most employees use past and out-of-date practices, experiences and knowledge and are not interested in updating knowledge and applying knowledge (Desivatte, Gordon, Rojo \& Olmos, 2015). Productivity in the health care sector is almost a new issue, as the measurement of productivity in the private sector, industries and factories has previously been studied (Sarma \& Barua, 2018).

Also, evaluating productivity, especially its effectiveness in the health sector, is not as easy as a production or commercial organization and is very complex because health services are of a different nature. In addition, the services cannot be stored. In addition, in measuring healthcare productivity, outputs cannot be easily converted to numbers (Eqbal, 2019). In this regard, Kumar, Singh, and Shankar (2015) researched the contribution and productivity of workers in research and development in a publicly funded research laboratory. The results showed that there is a positive and significant relationship between research productivity and development of researchers with participation in research and development projects. In a study, Desivatte et al. (2015) examined the impact of work and life culture on organizational productivity. The results show that they should increase the importance of promoting a good work-life culture and presenting work-life plans as increasing work productivity. Akbari and Ghaffari (2017) examined the relationship between knowledge management innovations and human resource empowerment. Research findings showed that five variables, type of knowledge, top managers, information technology, organizational culture and knowledge, have significant effect on human resource empowerment. Pawirosumarto, Setyadi, and Khumaedi (2017) investigated the impact of organizational culture on the performance of staff at the University of Mercado. The results show that there is a significant impact on engagement and mission on non- 
teaching staff performance. On the contrary, the two variables, cohesion and adaptation, do not have a significant impact on the performance of the staff of the University of Mercado. Simultaneous testing on variables, namely intervention, cohesion, adaptation, and mission, has a significant impact on employee performance. Ebrahimpour, Rahmani, and Baqal Asghari (2016) also investigated the role of knowledge management in employee productivity. Therefore, understanding the success factors of knowledge management and its application in organizations can be one of the important success factors. Therefore, in this article, we first discuss general concepts of knowledge management and its approaches and finally a model of human resource productivity in knowledge management will be presented. Also, the results of Shojaei, Jamali and Manteghi (2016) research on identifying factors affecting human resource productivity showed that as a result four factors: management, organizational motivation, empowerment and facilities were identified as effective factors on human resource productivity. Aminbidbakhti, Heydariyeh, and Rezvani (2013), in a study, investigated the factors affecting the productivity of human resources in the State Accounting Court and ways to increase it. The results show a significant relationship between all organizational factors and productivity, which had the most effect on the type and style of leadership on human resource productivity. Bahadori, Teymourzadeh, Mastri Farahani (2013) examined the factors that influence the productivity of human resources in a military health organization. This study showed that in evaluating human resource productivity in military health organization, attention should be paid to the components of mental and intellectual development, organizational support and organizational culture. Shekarchizadeh and Haji Ismaili (2015), in a review of human resource productivity models and their relationship to service quality in public service organizations. The results show that a set is more successful in its human resource efficiency to better identify the gap between human resource expectations and perceptions and the quality of its services, productivity and quality are two sides of a coin, one of which cannot be It took two elements but ignored the other, Although efficiency is essential to control costs, managers need to be aware of the inappropriate gap that is causing staffing disruption, and the quality of service as defined is needed to distinguish service and create loyalty in the workforce. Therefore, in addition to conducting applied research by the experts in the field of project management, the experts are encouraging university professors and other researchers to conduct research and applied studies and direct the activities of the university and research centers in order to solve the problems of project management in the country. Given this, knowledge sharing is a good solution to address communication deficiencies between universities and research centers under the supervision of the Ministry of Health and Medical Education. Today, in some health care organizations, productivity reduction and human resource stagnation have become a challenge; this may be due to the lack of optimal use of the organization's human resources, Therefore, if the factors affecting human resource productivity are identified, they can be enhanced by enhancing productivity in the organization (Mahram, 2011). Therefore, the purpose of this study was to identify the dimensions and components of human resources productivity in medical universities of Iran.

\section{Methodology}

The purpose of this study was applied and quantitative and qualitative mixed type of applied research and descriptive-correlational research method and fuzzy Delphi method were used. With features such as availability, experience, degree fit, doctorate or master's degree, university teaching, research experience and authorship in the field, 27 individuals were selected as the decision-making team in identifying indicators. The variables and dimensions of the variables were included in this study. Census method was used to determine sample size and snowball and census sampling method was used. Based on the fuzzy method, the decision maker comments are first collected and the answers are assigned to triangular fuzzy numbers. The assignment of triangular fuzzy numbers is because sometimes it is difficult to use integers to make decisions about such problems. In this way the experts are first selected and the problem is explained to them. Then a questionnaire is prepared and sent to these people. After the questionnaires are answered and collected, fuzzy 
calculations are performed on these comments. Responses are classified and agreements are announced. If a good consensus has been reached, a report from the Delphi process will be prepared and sent to the experts. If the consensus is not reached, the questionnaire should be redesigned and completed until the end (Shokohi \& Afrazeh, 2014). Table 1 is the conversion of verbal variables to triangular fuzzy numbers.

Table1. Conversion of Verbal Variables to Triangular Fuzzy Numbers

\begin{tabular}{cc}
\hline Verbal variables & Triangular fuzzy number \\
\hline Much & $(1,1,0.5)$ \\
\hline medium & $(1,0.5,0)$ \\
\hline Low & $(0.5,0.0)$ \\
\hline
\end{tabular}

In this study, based on the literature and research background, a conceptual model was designed to extract and screen the indicators and a questionnaire with a total of 7 dimensions and 50 indicators was designed. To the decision-making team. Their number was 27 based on non-random and snowball sampling. Table 2 shows the Cronbach's alpha values for each dimension. Cronbach's alpha values for structural-managerial factors 0.831, socio-psychological factors 0.721 , cultural factors 0.732 , individual factors 0.771 , economic factors 0.740 , environmental factors 0.803 And the factors that caused the intimacy and cooperation were 0.737 .

\section{Findings}

The decision-making team consisted of $14 \%$ female and $86 \%$ male respondents. Thirty-three percent of respondents had a master's degree, $4 \%$ a doctorate, $47 \%$ a doctorate, $8 \%$ a master's degree, and $8 \%$ a Ph.D. $15 \%$ of respondents had university degree, $44 \%$ assistant professor and $8 \%$ associate professor and 33\% other degree. $59 \%$ of the respondents were cooperating with faculty, $8 \%$ with teaching and $33 \%$ with others. $48 \%$ of respondents were between 5 and 11 years old, 4\% were between $11-15$ years old and 33\% were between 15 and 21 years old and 15\% were over 21 years old.

In this study, fuzzy Delphi method was used for extraction and screening of human resource indices at the University of Medical Sciences. The questionnaire was initially provided to the Delphi team. This questionnaire contains a total of 50 indicators. These indices were scored on the basis of success rates in the three high, medium and low levels, then the fuzzy mean of all the experts' opinions on each criterion was obtained, and its values were fuzzy decomposed. The fuzzy detoxification method used in this study is the surface center (center of gravity) method. The center of gravity of the surface below the diagram of the fuzzy membership function is defined as the definitive value of the fuzzy number.

$$
\mathrm{X}=\frac{(\mathrm{c}-\alpha)+(\mathrm{b}-\mathrm{a})}{3}+\mathrm{a}
$$

In this equation $\mathrm{X}$ the definitive number, $\mathrm{a}$ is the lower boundary of the membership function, $\mathrm{b}$ has the highest membership degree, and $\mathrm{c}$ is the upper boundary of the asymmetric triangular fuzzy membership function. The values for the fuzzy criteria averages are visible in Table 2. The definitive mean obtained indicates the degree of agreement of the experts with each of the components of the conceptual model of research. 
Table2. Fuzzy Mean of Expert Opinions in Survey and Fuzzy Determination Related to HRM Indicators

\begin{tabular}{|c|c|c|c|}
\hline Agents & Indicators & Fuzzy mean & $\begin{array}{c}\text { Average } \\
\text { Fuzzy Decomposition }\end{array}$ \\
\hline \multirow{3}{*}{$\begin{array}{l}\text { Structural-managerial } \\
\text { factors }\end{array}$} & $\begin{array}{l}\text { Discipline in work and time } \\
\text { management practices }\end{array}$ & $(1,0 / 82,0.3)$ & 0.74 \\
\hline & In-service training & $(1,0.620)$ & 0.56 \\
\hline & delegation of authority & $(1,0.620)$ & 0.56 \\
\hline \multirow{4}{*}{$\begin{array}{l}\text { Socio-psychological } \\
\text { factors }\end{array}$} & Job security & $(1,0.620)$ & 0.56 \\
\hline & Nondiscrimination & $(1,0.70,0)$ & 0.60 \\
\hline & Job rotation & $(1,0.48,0)$ & 0.49 \\
\hline & $\begin{array}{l}\text { Appropriate incentive and } \\
\text { punishment mechanisms }\end{array}$ & $(1,0.56,0)$ & 0.53 \\
\hline \multirow{4}{*}{ cultural factors } & Having a working conscience & $(1,0.63,0)$ & 0.57 \\
\hline & $\begin{array}{l}\text { Providing the opportunity to } \\
\text { express an opinion to do a } \\
\text { better job }\end{array}$ & $(1,0.65,0)$ & 0.58 \\
\hline & $\begin{array}{l}\text { Attempting to create } \\
\text { attitudes towards employee } \\
\text { productivity }\end{array}$ & $(1,0.46,0)$ & 0.47 \\
\hline & Having a teamwork spirit & $(1,0.70,0)$ & 0.60 \\
\hline \multirow{6}{*}{ Individual factors } & Work experience & $(1,0.27,0)$ & 0.38 \\
\hline & $\begin{array}{l}\text { There is a balance between } \\
\text { personal interests and jobs }\end{array}$ & $(1,0.48,0)$ & 0.49 \\
\hline & $\begin{array}{l}\text { One's attitude toward better } \\
\text { things }\end{array}$ & $(1,0.54,0)$ & 0.52 \\
\hline & $\begin{array}{l}\text { Occupational and general } \\
\text { occupational study rates }\end{array}$ & $(1,0.47,0)$ & 0.49 \\
\hline & $\begin{array}{l}\text { Ability to use computer } \\
\text { technology and the Internet }\end{array}$ & $(1,0.55,0)$ & 0.53 \\
\hline & $\begin{array}{ll}\begin{array}{l}\text { Providing } \\
\text { amenities }\end{array} & \text { appropriate } \\
\end{array}$ & $(1,0.40,0)$ & 0.45 \\
\hline \multirow{6}{*}{ Economic factors } & $\begin{array}{l}\text { Appropriate payment of cash } \\
\text { rewards }\end{array}$ & $(1,0.41,0)$ & 0.46 \\
\hline & $\begin{array}{l}\text { Appropriate payment of non- } \\
\text { cash rewards }\end{array}$ & $(1,0.43,0)$ & 0.47 \\
\hline & $\begin{array}{ll}\text { Employees' } & \text { economic } \\
\text { dependence } & \text { on the }\end{array}$ & $(1,0.52,0)$ & 0.51 \\
\hline & organization in individual life & & \\
\hline & $\begin{array}{l}\text { Increase employees' salaries } \\
\text { with regard to their } \\
\text { performance }\end{array}$ & $(1,0.51,0)$ & 0.50 \\
\hline & $\begin{array}{l}\text { Controlling the economic } \\
\text { conditions of the employees' } \\
\text { families from the organization }\end{array}$ & $(1,0.53,0)$ & 0.52 \\
\hline \multirow{5}{*}{ Environmental factors } & $\begin{array}{l}\text { Providing the minimum } \\
\text { physical standards required }\end{array}$ & $(1,0.59,0)$ & 0.55 \\
\hline & $\begin{array}{l}\text { How to install and install } \\
\text { equipment }\end{array}$ & $(1,0.41,0)$ & 0.45 \\
\hline & $\begin{array}{l}\text { Appropriate Sequences and } \\
\text { Sequences }\end{array}$ & $(1,0.29,0)$ & 0.39 \\
\hline & $\begin{array}{l}\text { Observing the principles of } \\
\text { safety and health in the } \\
\text { workplace }\end{array}$ & $(1,0.62,0)$ & 0.56 \\
\hline & $\begin{array}{c}\text { Competitors performance } \\
\text { evaluation }\end{array}$ & $(1,0.42,0)$ & 0.45 \\
\hline
\end{tabular}




\begin{tabular}{|c|c|c|c|c|}
\hline \multirow{5}{*}{\multicolumn{2}{|c|}{$\begin{array}{l}\text { Causing factors } \\
\text { Intimacy } \\
\text { Cooperation }\end{array}$}} & $\begin{array}{l}\text { Creating a framework for } \\
\text { staff participation and } \\
\text { decision making }\end{array}$ & $(1,0.52,0)$ & 0.51 \\
\hline & & Teamwork & $(1,0.63,0)$ & 0.57 \\
\hline & & Social relations & $(1,0.29,0)$ & 0.39 \\
\hline & & $\begin{array}{l}\text { Assist colleagues when } \\
\text { necessary }\end{array}$ & $(1,0.42,0)$ & 0.46 \\
\hline & & $\begin{array}{l}\text { Timely and fair reminder to } \\
\text { supervisors of staff mistakes }\end{array}$ & $(1,0.58,0)$ & 0.54 \\
\hline
\end{tabular}

By examining the results of the first phase of the survey, the fuzzy averages of the indices were reported to the experts in a questionnaire. Whereas the expert team members agreed with the indicators and the definitive mean of all criteria except the indicators of "having work experience", "proper arrangement and sequence of departments" and "social relations" above 0.4 So these 3 indicators were removed from the list of influential indicators. In the second phase of the expert survey, in addition to averaging the opinions of all the experts, the previous opinion of each expert was also recorded to compare their opinion on new indicators affecting human resource productivity. In the second questionnaire, 9 new indicators affecting human resource productivity were added by experts. Which are as follows:

1 - Ethnicity of the working group, 2- Working years of the working group, 3- Virtual education, 4- Nonformal meetings, 5- Family-based management (collective thinking), 6- Gender of the working group (Composition of members), 7- Scheduling the number of sessions (effective sessions), 8- Diversity of knowledge in a working group, 9- Applying suggestions to the organization

The new questionnaire was re-administered to the elite and the fuzzy and fuzzy mean regression was obtained for each index. The expert team members agreed with all the indicators in the second stage because the mean of the indicators are all above 0.4. The questions were re-submitted to the team without deletion or addition, and the survey was conducted for the third time, and the calculations were performed for the third stage. According to the views presented in the second step and compared with the results of the third step, if the difference between the two steps is less than the low threshold (0.1). In this case, the polling process will stop. The difference between the second and third stages of the survey is visible in Table 3 .

Table3. Differentiated fuzzy averaged stage II and III related HR indices

\begin{tabular}{|c|c|c|c|c|}
\hline Dimensions & Indicators & $\begin{array}{c}\text { Degraded Fuzzy } \\
\text { Mean Step } 2 \\
\end{array}$ & $\begin{array}{c}\text { Degraded Fuzzy } \\
\text { Mean Step } 3 \\
\end{array}$ & Discord \\
\hline \multirow{5}{*}{$\begin{array}{l}\text { Structural- } \\
\text { managerial factors }\end{array}$} & $\begin{array}{l}\text { Discipline in work and time } \\
\text { management practices }\end{array}$ & 0.73 & $0 / 64$ & $0 / 09$ \\
\hline & In-service training & 0.58 & $0 / 58$ & $0 / 00$ \\
\hline & Appropriate selection & 0.59 & $0 / 57$ & $0 / 02$ \\
\hline & Participatory Management & 0.57 & $0 / 59$ & $0 / 02$ \\
\hline & delegation of authority & 0.63 & $0 / 62$ & $0 / 01$ \\
\hline \multirow{3}{*}{$\begin{array}{l}\text { Socio-psychological } \\
\text { factors }\end{array}$} & Job security & 0.60 & $0 / 58$ & $0 / 02$ \\
\hline & Nondiscrimination & 0.59 & $0 / 59$ & $0 / 00$ \\
\hline & Job Satisfaction & 0.57 & $0 / 60$ & $0 / 03$ \\
\hline \multirow{6}{*}{ cultural factors } & Having a working conscience & 0.62 & $0 / 60$ & $0 / 02$ \\
\hline & $\begin{array}{l}\text { Providing the opportunity to express } \\
\text { an opinion to do a better job }\end{array}$ & 0.59 & $0 / 58$ & $0 / 01$ \\
\hline & $\begin{array}{l}\text { Attempting to create attitudes towards } \\
\text { employee productivity }\end{array}$ & 0.57 & $0 / 59$ & $0 / 02$ \\
\hline & work culture & 0.58 & $0 / 56$ & $0 / 02$ \\
\hline & $\begin{array}{l}\text { There is a balance between personal } \\
\text { interests and jobs }\end{array}$ & 0.55 & $0 / 56$ & $0 / 01$ \\
\hline & $\begin{array}{l}\text { Matching knowledge and education } \\
\text { with relevant job }\end{array}$ & 0.56 & $0 / 60$ & $0 / 04$ \\
\hline
\end{tabular}




\begin{tabular}{|c|c|c|c|c|}
\hline \multirow[t]{2}{*}{ Individual factors } & One's attitude toward better things & 0.61 & $0 / 58$ & $0 / 03$ \\
\hline & $\begin{array}{l}\text { Speed and accuracy in the execution of } \\
\text { tasks and tasks }\end{array}$ & 0.53 & $0 / 55$ & $0 / 02$ \\
\hline \multirow[b]{3}{*}{ Economic factors } & Providing appropriate amenities & 0.49 & $0 / 50$ & $0 / 01$ \\
\hline & Proper payment of cash rewards & 0.50 & $0 / 57$ & $0 / 07$ \\
\hline & $\begin{array}{l}\text { Appropriate payment of non-cash } \\
\text { rewards }\end{array}$ & 0.52 & $0 / 50$ & $0 / 02$ \\
\hline \multirow{4}{*}{$\begin{array}{l}\text { Environmental } \\
\text { factors }\end{array}$} & $\begin{array}{l}\text { Providing the minimum physical } \\
\text { standards required }\end{array}$ & 0.59 & $0 / 59$ & $0 / 00$ \\
\hline & How to set up equipment & 0.53 & $0 / 54$ & $0 / 01$ \\
\hline & $\begin{array}{l}\text { Observing the principles of safety and } \\
\text { health in the workplace }\end{array}$ & 0.50 & $0 / 52$ & $0 / 02$ \\
\hline & Competitors performance evaluation & 0.58 & $0 / 67$ & $0 / 09$ \\
\hline \multirow{4}{*}{$\begin{array}{l}\text { Causing factors } \\
\text { Intimacy and } \\
\text { Cooperation }\end{array}$} & $\begin{array}{l}\text { Creating a framework for staff } \\
\text { participation and decision making }\end{array}$ & 0.55 & $0 / 58$ & $0 / 03$ \\
\hline & Teamwork & 0.58 & $0 / 59$ & $0 / 01$ \\
\hline & Assist colleagues when necessary & 0.51 & $0 / 53$ & $0 / 02$ \\
\hline & $\begin{array}{l}\text { Timely and fair reminder to } \\
\text { supervisors of staff mistakes }\end{array}$ & 0.50 & $0 / 54$ & $0 / 04$ \\
\hline
\end{tabular}

According to the views presented in the third stage and compared with the results of the second stage, the mean difference between the two stages is lower than the low threshold $(0.1)$, so the polling process stops and members the expert group agreed with all the indices and these indices were adopted based on the fuzzy Delphi technique. The conceptual model of research to extract dimensions and indicators is as follows:

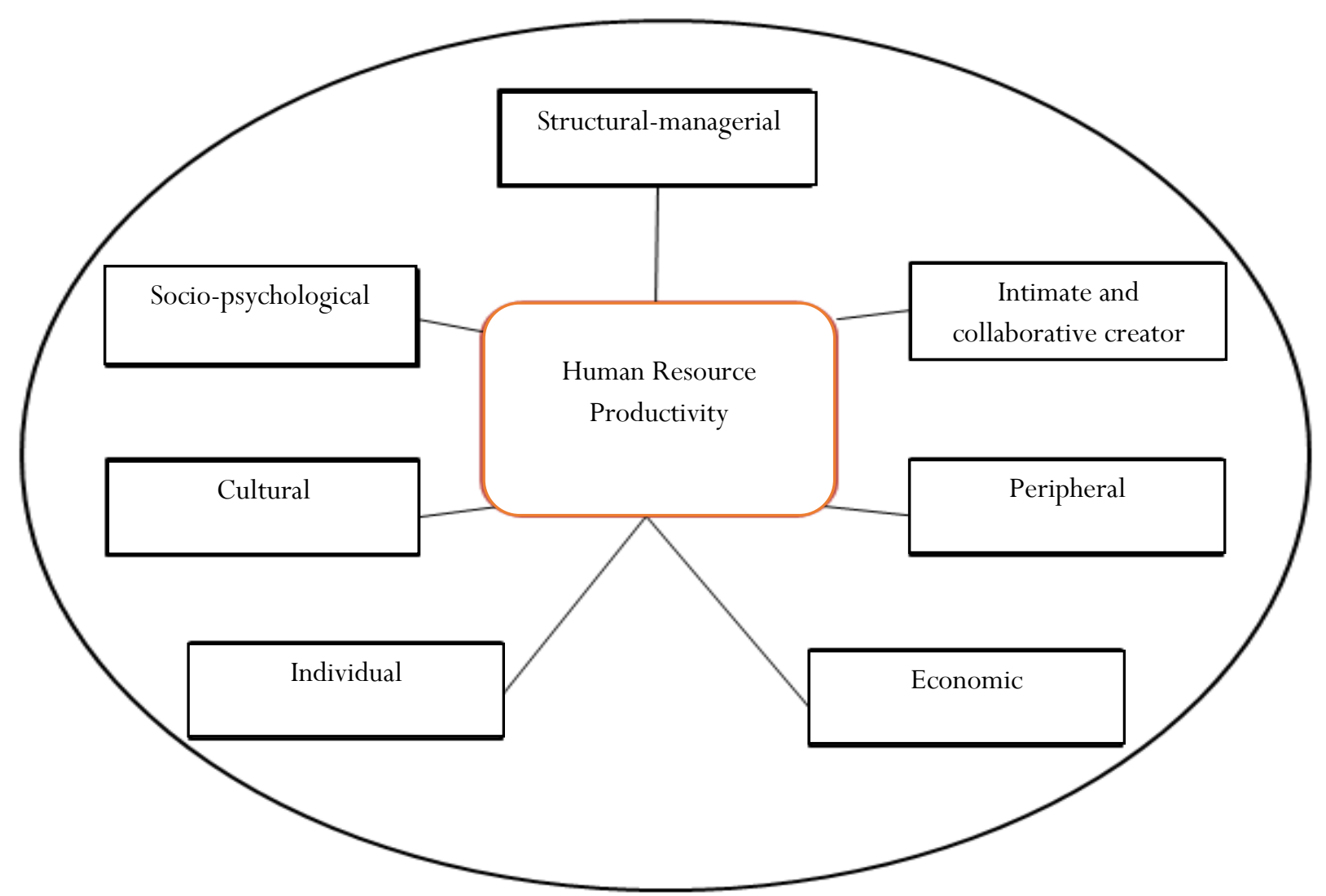

Figure1. Conceptual Research Pattern 


\section{Discussion}

Human Resource Productivity shows that there are generally seven main categories (StructuralManagerial, Social-Psychological, Cultural, Individual, Economic, Environmental, Intimate and Collaborative) with 56 sub-indices, Human Resource Productivity Indicators Make up. Therefore, due to the development of the present research, in the form of a research question, human resource productivity indices of medical sciences universities were identified. In addition to HR, some indicators that appeared to be HRM indicators were identified and subjected to expert evaluation by a questionnaire. The questionnaire asked respondents to rate the importance of each of the 50 items. The questionnaire used a three-spectral continuum, ranging from "high" to "low". At this stage fuzzy Delphi method was used to identify and extract the indices. According to experts, out of the 50 items that were put forward as potential indicators for realizing human resources productivity in medical sciences universities, according to the experts, 9 items were added and 3 items were removed and in seven general categories. (Structural-managerial factors, cultural factors, individual factors, economic factors, environmental factors, intimate and cooperative factors, socio-psychological factors) were classified as described in Table 5.

Table4. Identified HRM Indices Using Fuzzy Delphi

\begin{tabular}{|c|c|}
\hline Agents & Indicators \\
\hline \multirow{5}{*}{ Structural-managerial factors } & Discipline in work and time management practices \\
\hline & In-service training \\
\hline & Appropriate selection \\
\hline & Participatory Management \\
\hline & delegation of authority \\
\hline \multirow{4}{*}{ Socio-psychological factors } & Job security \\
\hline & Nondiscrimination \\
\hline & Job Satisfaction \\
\hline & Good relationship between manager and staff \\
\hline \multirow{4}{*}{ cultural factors } & Having a working conscience \\
\hline & Providing the opportunity to express an opinion to do a better job \\
\hline & Attempting to create attitudes towards employee productivity \\
\hline & work culture \\
\hline \multirow{7}{*}{ Individual factors } & There is a balance between personal interests and jobs \\
\hline & Matching knowledge and education with relevant job \\
\hline & One's attitude toward better things \\
\hline & Speed and accuracy in performing tasks and tasks \\
\hline & Psychological and physical balance of staff \\
\hline & Occupational and general occupational study rates \\
\hline & Working Group Years \\
\hline \multirow{3}{*}{ Economic factors } & Providing appropriate amenities \\
\hline & Proper payment of cash rewards \\
\hline & Appropriate payment of non-cash rewards \\
\hline \multirow{3}{*}{ Environmental factors } & Providing the minimum physical standards required \\
\hline & How to install and install equipment \\
\hline & Observing the principles of occupational health and safety \\
\hline \multirow{4}{*}{$\begin{array}{l}\text { Causing factors } \\
\text { Intimacy and Cooperation }\end{array}$} & Creating a framework for staff participation and decision making \\
\hline & Teamwork \\
\hline & Assist colleagues when necessary \\
\hline & Timely and fair reminder to supervisors of staff mistakes \\
\hline
\end{tabular}

In explaining the results, it can be stated that productivity is a subject that is looked at in different dimensions and its application and importance are becoming more and more evident every day. Productivity is a common theme in economics and management that is addressed in both the economics and management books. Efforts to improve and efficiently utilize a variety of resources, such as labor, capital, materials, energy 
and information, are aimed at all managers of economic organizations and industrial production units and service institutions. Having the right organizational structure, efficient execution procedures, healthy work equipment and tools, a balanced work environment, and most importantly, qualified and competent staff are essentials that managers need to achieve in order to achieve optimal productivity. Employees' involvement in their conscious and conscious work and efforts, together with their work discipline, can affect productivity and repair to improve productivity, especially in a turbulent and insecure environment. The spirit of productivity improvement should be embodied in the body of the organization in which the workforce forms the core. One of the most important goals in any organization is to improve its productivity level, and given that human beings play a central role in creating productivity, their demands on the organization have a key impact.

Many studies have been carried out on the factors affecting human resource productivity in Iran and in the world. The overall aim of all these researches is to achieve specific priorities appropriate for each organization to improve productivity. Etezadi (2017) conducted a study on the factors affecting the increase of manpower productivity in the electricity company and the results showed that the effective factors were classified into four categories: individual factors, organizational or managerial factors, factors Concerning organizational support and compensation system, organizational environment factors are in line with the results of the present study. Shojaei et al. (2016) conducted a study identifying the factors affecting human resource productivity and thus identified four factors: management, organizational motivation, empowerment, and facilities as effective factors on human resource productivity. Is present. Baradaran and Valijani (2016) conducted a study on the factors affecting the promotion of human resource productivity in the Tax Administration of Iran (case study of the General Department of Taxation of East Tehran) and the results show, respectively, three factors Organizational, personal, and environmental characteristics have the greatest impact on productivity enhancement, which is consistent with the results of the present study. Salajegheh and Reyhani Yasawoli(2016) conducted a research on human resource productivity model design at Mashhad University of Medical Sciences using Delphi method and the results of research included identifying 45 effective factors on human resource productivity and classification. It is in organizational and individual dimensions that is in line with the results of the present study. AllahVerdi, Farahabadi and Sajadi(2009) conducted a research to prioritize the factors affecting human resource productivity from the viewpoints of middle managers of Isfahan University of Medical Sciences, and the results showed that reforming employment systems and organizational structures, Job enrichment, training planning as needed, delegating authority to mid-level managers, and supervising decision making, implementing incentive programs can be effective in enhancing human resource productivity and thereby enhancing the health system. This is in line with the results of the present study. Marelli and Signorelli (2015) conducted a study identifying human resource efficiency indicators in German hospitals which results showed that human resource efficiency indicators in German hospitals are 1 - Emotional intelligence, 2- Flexibility of work, 3Organizational citizenship behavior, 4- Good communication, 5- Understanding the necessity of productivity, 6- Communication skills and 7- Good participation which is in line with the results of the present study. In a study, Desivatte etal (2015) examined the impact of work and life culture on organizational productivity. The results show that the importance of promoting a good work-life culture and presenting work-life plans as increasing work productivity should be in line with the results of the present study. Edison and Walter (2015) conducted a study on labor productivity in Australia's small and large industries, and the results showed that Australia's large industrial labor force had higher productivity than small industries. This is in line with the results of the present study. Kudyba(2003) has investigated the factors affecting organizational productivity and productivity. Research findings show that by appropriate training, guidance and participation of employees can improve their skills and increase organizational efficiency, which is in line with the results of the present study. 
Therefore, given the limited resources and facilities available to the organization, many resources are nonrenewable or require many years of re-formation or some are scarce, so providing these resources at a high cost Needs, as well as increasing population and consequently increasing consumption and production, day by day increases resource constraints, so it is never possible to satisfy unlimited needs by relying on such resources and facilities. So the only logical and feasible way is to maximize Productivity and utility are the least of the resources, and this is more about productivity and attention It can benefit the organization and the society in which the organization is located. Human resource productivity is the most important measure of productivity. Because it is an essential element in any effort to improve human resource productivity. Overall, it should be acknowledged that the activities of each organization are influenced by a set of factors that can be identified and investigated effectively in order to improve the activities and achieve the organizational goals. On the other hand, as productivity is a function of many different factors, which are influenced by the mission, activity, operations, and factors of such organization from one organization to another, and the importance and impact of these factors on the productivity of different organizations are not the same. Therefore, it is not possible for organizations to get involved in all areas of influence. The need to achieve the highest productivity first needs to be identified and prioritized in terms of importance to the organization in accordance with scientific criteria and then formulated to improve productivity, implementation plans and plans. Finally suggested. Understand the role and impact of staff participation in organizational performance in medical sciences in cultural contexts, as well as the ability and ability to use technical information for managers to perform assessments correctly. 


\section{References}

Ahmadi A. (2016). The Relationship between Creativity and Innovation with Human Resource Productivity. New Approaches to Educational Management, 7 (3): 222-209.

Akbari N, Ghaffari M. (2017). Verifying relationship of knowledge management initiatives and the empowerment of human resources. Journal of Knowledge Management; 21(5):1120-1141.

Allahverdi M, Farahabadi S M, Sajadi H. (2009). Prioritizing Factors Affecting Human Resource Productivity from the Viewpoints of Middle Managers of Isfahan University of Medical Sciences. Hospital Quarterly, 9 (4): 85-77.

Alnadi L T. (2019). Strategic Audit of Human Resource Management and its Effect on the Efficiency of Employees in the Jordanian Customs Department. International Journal of Academic Research in Business and Social Sciences; 9(3).

Aminbidbakhti A, Heydariyeh S A, Rezvani M. (2013). Investigating the Factors Affecting Human Resources Productivity in the State Accounting Court and Strategies for Increasing It, Auditing Knowledge Quarterly, 13(53): 18-2.

Bahadori M K, Teymourzadeh E, Mastri Farahani H. (2013). Influencing Components of Increasing Human Resource Productivity in a Military Health Organization, Journal of Military Medicine, 15 (1): 75-86.

Bahmani A, Fojali T. (2017). The Relationship between Transformational Leadership and Human Resource Productivity with Consideration of the Mediating Role of Spirituality in the Workplace. Journal of Human Resource Studies, 26 (11): $63-50$.

Baradaran V, Valijani M. (2016). Investigating the Factors Affecting the Improvement of Human Resource Productivity in the Tax Administration of Iran (Case Study: East Tehran Tax Administration), Journal of Tax Research, 24(29): 165-184

Desivatte I, Gordon JR, Rojo P, Olmos R. (2015). The impact of work-life culture on organizational productivity, Personnel Review; 44 (6): 883 - 905.

Ebrahimpour H, Rahmani N, Bagal Asghari P. (2016). The Role of Knowledge Management in Employee Productivity. International Conference on Management Elite, Iran-Tehran, International Conference Hall of Shahid Beheshti University.

Edison T, Walter H. (2015) Productivity in the Australian small and large industries, Journal of Services Marketing; 30 (2): 238 254

Eqbal A. (2019). The strategic human resource management approaches and organizational performance: The mediating role of creative climate. Journal of Advances in Management Research; 16(2): 181-193.

Etezadi Sh. (2017). Investigating the Effective Factors on Increasing Human Resources Productivity in Power Company, 12th National Conference on Quality and Productivity.

Kudyba S. (2003). Knowledge management: The art of enhancing productivity and innovation with the human resource in your organization. Published in DM Review, April

Kumar R, Singh R K, Shankar R. (2015). Critical success factors for implementation of supply chain management in Indian small and medium enterprises and their impact on performance. IIMB Management Review, 27(2): 92-104.

Mahram B. (2011). Greater productivity of labor in the university system, through the Management system review.

Marelli E, Signorelli M. (2015) Identification of Human Resource Efficiency Indicators in Hospitals in Germany; 31 (7) :732-754.

Mash R, Adler O. (2018). Human Resource Managers' Role Perception and Their Conflict Management Style. Journal of Sociology; 6(1): 41-55.

Pawirosumarto S, Setyadi A, Khumaedi E, (2017) "The influence of organizational culture on the performance of employees at University of Mercu Buana", International Journal of Law and Management;59(6): 950-963.

Salajegheh S, Reyhani Yasawoli A. (2016). Designing a Human Resources Productivity Model at Mashhad University of Medical Sciences by Delphi Method, First National Conference on Organizational Transformation and Innovation with Resistance Economics Approach.

Sarma A, Barua P. (2018). Challenges of Human Resource Management in Hospitals and their probable solutions: A study based on review of literature. Journal of Management in Practice (Online Only), 3(1).

Shekarchizadeh A R, Haji Ismaili S. (2015). A review of human resource productivity models and their relationship to service quality

Shojaei S S, Jamali Gh, Manteghi N. (2016). Identifying Factors Affecting Human Resource Productivity, Journal of Human Resource Management Research, Imam Hussein University of Technology, 2(1): 1-6

Shokohi S, Afrazeh A. (2014). Designing Technology Transfer Model and Nanoscience in Iran Using Fuzzy Delphi Method, Journal of Technology Growth. 11(41).

Taheri Sh. (2017). Productivity and its Analysis in Organizations, Tehran: Journal, 16th Edition.

Terzieo V, Banabakoa V, Gorgieo M. (2018). Social activity of human resource as a basis of effective social policy. Available at SSRN 3138140. 